\title{
Waldisa Rússio: museologia e política nos anos 1980
}

\author{
Waldisa Rússio: museology and politics in 1980
}

https://doi.org/10.1590/1982-02672020v28d2e58

\section{INÊS GOUVEIA'}

https://orcid.org/0000-0003-4783-9033

Universidade de São Paulo / São Paulo, SP, Brasil

RESUMO: Este artigo utiliza a trajetória da paulistana Waldisa Rússio para observar quais temas mais mobilizaram os agentes brasileiros do campo museológico nos anos 1980. Para isso, situam-se algumas das instituições de então, privilegiando aquelas cujas ações tinham alguma repercussão nacional. Deste modo, observa-se com quais capitais simbólicos Waldisa se inseriu no campo para se alçar progressivamente à condição de autoridade, a ponto de ser ouvida e considerada. Destaca-se como o processo de regulamentação da profissão de museólogo(a) foi marcado por diferentes posições, especialmente sobre qual base do conhecimento habilitaria o profissional para esse labor. Também sobre a produção desse conhecimento, a elaboração teórica da museologia é problematizada como etapa que marca o desenvolvimento do campo. Destaca-se então o protagonismo de Waldisa Rússio ao aliar as dimensões conceitual e política dos museus. Considerou-se sua experiência acumulada nos anos 1980 e sua interlocução com o campo do patrimônio paulista. Relativamente a isso, são mencionados os contextos em que ela se engajou na elaboração de políiticas públicas museológicas. Conclui-se que, a despeito do debate quanto à dimensão política da preservação nos anos 1980, em razão inclusive da redemocratização do país, o campo museológico praticamente passou ao largo dessa discussão.

\begin{abstract}
1. Doutora em Museologia e Patrimônio pelo Programa de Pós-Graduação em Museologia e Patrimônio (PPG-PMUS) da Universidade Federal do Estado do Rio de Janeiro (Unirio) e do Museu de Astronomia e Ciências Afins (Mast), mestra em Memória Social pelo Programa de Pós-Graduação em Memória Social (PPGMS) da Unirio e historiadora pela Faculdade de Formação de Professores da Universidade do Estado do Rio de Janeiro (FFP-UERJ), com especialização em Sociomuseologia pelo Curso de Estudos Avançados de Museologia (Ceam) da Universidade Federal da Bahia (UFBA) e da Universidade Lusófona de Humanidades e Tecnologias (ULHT). Atuou na articulação da Rede de Museologia Social do Rio de Janeiro (2013-2019). É professora do Instituto de Estudos Brasileiros da Universidade de São Paulo (IEB/USP). E-mail: <inescgouveia@gmail.com>.
\end{abstract}


ABSTRACT: This article proposes to use São Paulo museologist Waldisa Rússio's life trajectory to verify which topics mobilized Brazilian agents the most in the museological context during the 1980s. In this regard, it uses some of the institutions of that time, prioritizing those whose actions showed some kind of national repercussion. Therefore, it should be noted with which symbolic capitals Waldisa entered the field in pursuance of progressively reaching the condition of authority to be heard and considered. The article highlights how the regulatory process of museum studies was impacted by different positions, especially about which knowledge basis would empower such labor. Further about the production of this knowledge, the theoretical elaboration in museology is thought of as a step that affects the development of the area. Waldisa Rússio's guiding role stands out then by combining the conceptual and political dimensions of museums. In the process the article makes the case for Rússio's experience accumulated in the 1980s and her interlocution with São Paulo heritage. Bound up with this are the contexts she engaged with to elaborate public policies in museology. Despite the debate regarding the political magnitude of preservation in the 1980s, on account of the country's own redemocratization process, museology was shown to have practically missed such discussion.

KEYWORDS: Waldisa Rússio. Museology. The policies of museology. 1980s. 
INTRODUÇÃO

Conforme se observa na literatura sobre as políticas culturais e de acordo com o que foi debatido no evento Democracia, Patrimônio e Direitos, ${ }^{2}$ sabemos que nos anos 1980 os critérios utilizados para a preservação foram repensados. $\bigcirc$ patrimônio, não apenas no plano conceitual e discursivo, foi afetado pela emergência da luta pela ampliação dos direitos civis, que ganhou o debate público em razão da redemocratização do país. Esse movimento resultou na definição sumária do papel do Estado quanto aos direitos culturais e patrimoniais, conforme explicitado na Constituição Federal, nos artigos 215 e 216 . Antes dos anos 1970 e 1980, os critérios gerais que balizavam a ação de preservação do patrimônio eram as dimensões histórica e artística, atreladas à materialidade dos bens culturais. A transformação dos anos 1980 pôs, ao menos discursivamente, as diversas "manifestações das culturas populares, indígenas e afro-brasileiras, e das de outros grupos participantes do processo civilizatório nacional" sob a responsabilidade do Estado. ${ }^{3}$ Trata-se de um passo importante para ampliar as camadas sociais representadas na ação de preservação, bem como as características dos bens protegidos. Foi a partir dessa base que as ações do patrimônio imaterial puderam se desenvolver nos anos 2000.

Essa transformação passada nos anos 1980 teria acontecido também na concepção de preservação partilhada no campo museológico? De acordo com as análises empreendidas, que embasam as considerações apresentadas a seguir, a despeito das críticas aos museus, repercutidas internacionalmente desde os anos 1960, o campo museológico pouco aderiu à transformação.

Diante disso, o objetivo deste texto é refletir sobre como o campo museológico nacional lidou com a politização da preservação e problematizar os motivos pelos quais seu engajamento não foi análogo ao do patrimônio. Entre as formas possíveis para fazê-lo, optei por partir da trajetória de uma museóloga. Agente ativa na relação com os sujeitos e as instituições da museologia paulista, nacional e internacional, Waldisa Rússio Camargo Guarnieri participou dos principais processos e eventos da área nas décadas de 1970 e 1980. Consultando a vasta documentação legada por ela, ${ }^{4}$ pode-se identificar os principais temas, consensos e dissensos que marcaram a comunicação entre as e os agentes nesse período. A análise por meio da trajetória de Waldisa também é oportuna porque ela participou ativamente do ensejo de abertura conceitual da noção de museu e museologia. Ela visava influenciar as atividades práticas empreendidas pelas instituições e projetou isso em termos de políticas públicas.
2. Trata-se do Seminário Democracia, Patrimônio e Direitos: a década de 1980 em perspectiva, realizado nos dias 10 e 11 de junho de 2019 na Universidade de São Paulo, em São Paulo. Agradeço às pessoas que trabalharam para a realização do evento e para o prosseguimento dos debates com a publicação deste dossiê, especialmente às professoras Márcia Chuva (Unirio) e Flávia Brito do Nascimento (USP).

3. Brasil (1988).

4. Refiro-me principalmente ao seu fundo no Arquivo do Instituto de Estudos Brasileiros da Universidade de São Paulo (IEB/USP) e ao arquivo do Curso/Instituto de Museologia da Fundação Escola de Sociologia e Política. 
5. Esse movimento de elaboração da história do campo tem relação com a ampliação do número de cursos de graduação e pós-graduação e, de modo integralmente relacionado, com o aumento de publicações especializadas e a ocorrência de encontros e redes, como o Seminário Brasileiro de Museologia e os fóruns nacionais e estaduais de museus.

6. Bourdieu (2003).

7. Cf. Gouveia (2018).

8. Conforme a perspectiva bourdieuana, um dos aspectos da dinâmica dos campos é a circulação da sua produção, a disseminação das ideias e conceitos, por exemplo, nas publicações e replicações em temários de eventos. Outro aspecto a se considerar - que não foi explorado neste estudo e é passível de análise para se observar a reprodução das ideias - é a conferências de prêmios, menções honrosas e outros méritos públicos (Bourdieu, op. cit.). Considero que, num campo recente como o museológico, a análise desses aspectos está facilitada, seja pela possível existência de fontes escritas ou pela possibilidade de obter testemunhos orais das e dos agentes que participaram do contexto dessa formulação, como é o caso.
Um dos propósitos para a realização desta pesquisa - e também deste artigo - foi participar do intento de historicizar o campo museológico, que viveu uma expansão entre os anos de 2003 e 2015 no Brasil. ${ }^{5}$ Também é uma opção por valorizar os acervos disponíveis para a análise deste campo, que possibilitam investigar sentidos em disputa em torno das ideias de cultura, memória, museu, patrimônio etc. Outra motivação é a análise do protagonismo de uma mulher que, contrariando as imposições sociais de sua geração (ditas e não ditas), teve uma carreira profissional ativa e contínua, inserindo-se na elaboração intelectual e política. Nessa direção, também se estima contribuir com o próprio exercício metodológico que prevê a análise de um contexto histórico pela observação da trajetória de uma pessoa, objetivando suas escolhas e percursos. Além disso, pareceu significativa a possibilidade de enfatizar mais os dissensos, as descontinuidades e as rupturas, que muitas vezes são apagadas das narrativas oficiais das instituições.

De um ponto de vista teórico e metodológico, utilizou-se na pesquisa a perspectiva de campo elaborada na sociologia de Pierre Bourdieu. ${ }^{\circ}$ Não caberá aqui explicitar as causas e consequências dessa opção, mas vale dizer que dela derivam os sentidos empregados de "agentes", "posições", "autonomia de campo", "capital simbólico" etc. Também decorre dessa escolha a compreensão da relação de aproximação, dependência e interseção entre os campos. De modo geral, seguem-se algumas das considerações/conclusões a que se chegou na pesquisa de doutorado, a partir da análise de fontes documentais e entrevistas e com auxilio da bibliografia de referência; ${ }^{7}$ e cruzam-se a política das relações, a elaboração política da preservação e o ensejo de formulação de políiticas públicas para o campo museológico.

\section{A POLÍTICA ENTRE OS AGENTES MUSEOLÓGICOS}

Um campo recente - como o que aglutina a museologia, os museus e a práxis da musealização - favorece a análise de sua produção, circulação de ideias, suas reproduções e transformações. ${ }^{8}$ Considerando que o campo em questão é um campo cultural locupado de elaborar critérios de preservação para museus, justificá-los em termos consistentes e fazê-los impactar a maneira como se pensa e se faz a musealização), vale problematizar: quais são suas regras e o quanto seus agentes as obedecem ou as subvertem; e como são formulados e implementados os valores da preservação com os quais o trabalho museológico lida.

Waldisa Rússio passou a atuar regularmente na museologia paulista e nacional a partir dos anos 1970. Nessa década e na seguinte, o campo museológico 
brasileiro estava formalmente organizado em torno das seguintes instituições: ${ }^{9}$ museus, cursos de formação em museologia, o Comitê Brasileiro do Conselho Internacional de Museus (lcom-BR), associações de classe, conselhos profissionais e instâncias da administração pública. Esses eram os principais agentes responsáveis por reelaborar uma tradição eurocentrada e, junto com isso, promover uma discussão em torno da importância do fazer dessas instituições. Alguns desses agentes também se dedicavam à elaboração teórica e prática da dimensão política e pública dos museus. A vida cotidiana das relações se efetivava em torno de atos concretos que registravam, divulgavam e consagravam aquilo que se buscava normalizar e naturalizar. Refiro-me a normativas jurídicas, pactuações políticas e administrativas, publicações, premiações, temas de eventos e outros acontecimentos com capacidade similar de produzir repercussão e adesão. Os agentes (indivíduos e instituições) buscavam suas frentes de atuação para se firmarem como fontes oficiais, reconhecidas, de produção e reprodução do conhecimento museológico.

Entre os anos 1960 e 1970 houve um incremento na formação em museologia no país. Os três novos cursos criados precisaram se reportar à tradição do Curso de Museus, fundado em 1932, no Museu Histórico Nacional (MHN), no Rio de Janeiro, ${ }^{10}$ que formou gerações de profissionais, atuantes em museus de diversos estados. Ainda nos anos 1970, o foco desse curso foi a dimensão material e técnica dos acervos. Ele teve alterações significativas em seu currículo no fim dessa década e na seguinte, deslocando seu centro do museu para a museologia e dando cada vez mais destaque ao aspecto teórico da disciplina. ${ }^{11} \bigcirc$ segundo curso do Rio de Janeiro, criado em 1975 na Faculdade de Arqueologia e Museologia Marechal Rondon, ${ }^{12}$ conforme diz o nome, estava mais próximo da arqueologia e também dos conhecimentos técnicos, tendo como professores os egressos do Curso de Museus do MHN. Por sua vez, criado em 1969, o Curso da Universidade Federal da Bahia guardou estreita relação com a história, com a filosofia e, paulatinamente, com a educação. Também teve a influência do Curso de Museus carioca em sua grade inicial, mas a partir das primeiras turmas alterou seu currículo e quadro docente. ${ }^{13}$ Em 1977, com a liderança de Waldisa Rússio, foi criado em São Paulo o primeiro curso de pós-graduação na área, mais próximo das ciências humanas e sociais, notadamente da sociologia.

As instituições que pretensamente organizavam a interlocução nacional e internacional estavam situadas no Rio de Janeiro e muito vinculadas a uma perspectiva tradicionalista da conservação e preservação. Inclusive por uma questão geracional, muitos desses agentes que compartilharam com Waldisa Rússio as posições de influência nos anos 1980 (à frente de instituições e cursos) haviam sido formados ainda na tradição barroseana. ${ }^{14}$ Refiro-me especialmente à Associação Brasileira de
9. Esta relação não é exaustiva. Diante da impossibilidade de observar todas as instituições existentes, dá-se destaque àquelas que tinham a pretensão de interlocução nacional e foram mais recorrentes na trajetória de Waldisa Rússio.

10. Criado no MHN e posteriormente instituído no que hoje é a Universidade Federal do Estado do Rio de Janeiro (Unirio).

11. Cf. Sá (2014).

12. Esse curso foi finalizado e continuado, de modo indireto, nas Faculdades Integradas Estácio de Sá, durando aproximadamente vinte anos.

13. Cf. Gouveia, op. cit.

14. Referimo-nos a Gustavo Barroso, fundador do MHN, mentor e professor do Curso de Museus e autor de Introdução à técnica de museus, bibliografia que serviu aos estudos de muitas gerações, com alcance e expressão nacional. Tais agentes, em sua maioria mulheres museólogas, professoras e professores, profissionais, agentes públicos, diretores e presidentes de instituições, haviam se formado no Curso de Museus do MHN (Magalhães, 2006). 
15. A ABM foi fundada por egressas e egressos do Curso de Museus do MHN, nos anos 1960. Nos anos $1970 \mathrm{e}$ 1980, o Icom-BR também era presidido por egressas do mesmo curso. Vale considerar que Gustavo Barroso esteve no MHN e no Curso de Museus até o fim dos anos 1950. Não houve, nesse período e contexto de formação, uma ruptura com seu pensamento nem nenhuma alteração significativa nos conteúdos do curso, o que só parece ter ocorrido, conforme argumenta a bibliografia aqui referida, a partir dos anos 1970. Cf. Gouveia, op. cit.

16. Cf. Julião (2001); Chagas (2006).
Museus (ABM) e ao lcom-BR, responsáveis pela organização de eventos nacionais, a exemplo dos Congressos Nacionais de Museus. ${ }^{15}$

Sendo uma herança da dominação colonial no Brasil, foi no século passado que os museus tiveram uma significativa ampliação quantitativa. Na primeira metade do século, esse movimento teve relação com a ação do Estado, na construção de uma identidade nacional. Na segunda metade, passou a ser mais frequente a criação de museus regionais, e também se observa uma diversificação nas suas temáticas. ${ }^{16}$ Nacionais ou regionais, mesmo com tipologias diversas, esses museus estavam majoritariamente ligados a uma elite intelectual e econômica. Na medida em que seus profissionais vinham desse estrato social, suas versões e representações (da história, da arte e do conhecimento científico) conformavam narrativas uníssonas, com pouca correspondência àquilo que hoje reconhecemos ser a diversidade cultural brasileira. Observando os registros dos eventos, as publicações, os conteúdos dos cursos, as matérias de jornais e os documentos, vê-se que o enfoque elitista da ação de preservação praticamente não era objeto de reflexão.

É sabido que houve considerável influência do debate internacional na mudança do temário na museologia brasileira ao longo do século XX. Nos anos 1970 e 1980, agentes que estavam em interlocução com museus, cursos e associações em outros países traziam e traduziam as questões em pauta. Aqueles, no entanto, que ocupavam lugares dominantes (presidindo posições de interlocução nacional, organizando eventos, detendo condições simbólicas e materiais de prover a circulação de suas ideias etc.) buscaram uma ampliação sem rupturas, comportando ao mesmo tempo a tradição barroseana e alguma expressão das indagações sobre as funções dos museus. As evidências disso podem ser observadas, por exemplo, por meio do Comitê Brasileiro do Icom. A esse respeito, tomo a obra Introdução ao ensino dirigido de museologia, de autoria de Fernanda de Camargo e Almeida Moro e de Lourdes M. Martins do Rego Novaes (Figuras 1, 2 e 3). O livro de 1977 foi editado pela Associação de Membros do Icom no Brasil, instituição que acabou por se transformar no Icom-BR, presidido pelas próprias autoras. Dedicada a Gustavo Barroso, a publicação apresenta um conjunto de indagações a respeito das atividades desempenhadas pelos museus, com relação aos seus acervos. Na introdução, as autoras afirmam seu desejo de "despertar reflexões mais profundas sobre os diversos problemas de um museu" e acrescentam:

Se o museu atual deve representar uma resposta concreta para as várias dúvidas de diversos campos através do diálogo de suas colecções, estejam elas em exposição ou em reserva técnica, não podemos esquecer do mecanismo que o museu necessita para sua sobrevivência e, é aí que está o trabalho do museólogo: na documentação, na classificação, na 
leitura museológica, na pesquisa, na manutenção e conservação das coleções, no planejamento das exposições, na cooperação de apoio à ação educativa e cultural integrada, bem como na planificação de novos museus. ${ }^{17}$
17. Moro; Novaes (1977, p. 11)

18. Ibid.

INTRODUÇAOO AO ENSINO DIEIGIDO DE MUSEOLOGIA

EXERCICIOS I

por fernanda de camargo e almeida-MORO

e lourdes m.m. do rego novaes

\section{7}

editado por: Associação de Membros do ICOM AMICOM - BR. Comité Brasileiro do International Council of Museums MOUSEION - Centro de Estudos Museológicos e de Ciềncias do Homem

Figura 1 - Contracapa do livro Introdução ao ensino dirigido de museologia. ${ }^{18}$ 
Introdução

Exercício Introdutório

I - Definições, Conceitos Antigos e Atuais . .

II - Aquisição de Peças

III - Organização de Museus e Coleções ..... 23

IV — Documentação $\ldots \ldots \ldots \ldots \ldots \ldots \ldots . \quad 30$

$\mathrm{V}$ - Pesquisa $\ldots \ldots \ldots \ldots \ldots \ldots \ldots \ldots \ldots \ldots \ldots \ldots \ldots$

VI - Manutenção e Conservação das Coleções 48

VII - Arquitetura e Localização ......... 65

VIII - Equipamento $\ldots \ldots \ldots \ldots \ldots \ldots \ldots \ldots .75$

IX - Exposição ................ 79

X - Segurança dos Museus e Coleções ..... 90

XI - Ação Educativa e Cultural ......... 105

XII - Administração dos Museus e Coleções . 125

XIII - Exercício Final $\ldots \ldots \ldots \ldots \ldots \ldots \ldots$

Cada exercício é seguido de bibliografia específica.

Figura 2 - Sumário do livro Introdução ao ensino dirigido de museologia. ${ }^{19}$ 
Através da experiência que tivemos ao dirigirmos a Unidade de Treinamento da AMICOM-BR., nos últimos cinco anos, juntamente com as pesquisas e programas aplicados que vimos realizando para a MOUSEION-Centro de Estudos Museológicos e de Ciências do Homem, sentimos, mais do que nunca, a carência que havia, ao mesmo tempo, de provocar situações práticas, e de despertar reflexões mais profundas sobre os diversos problemas de um museu. Buscamos então por meio de perguntas levar o profissional de museologia, museólogo, a um raciocinio que the mostraria o caminho a seguir.

As perguntas são sem respostas, acompanhadas de bibliografia especifica moderna e atualizada. Mas as respostas estáo contidas nas perguntas que se seguem, no diálogo profissional, na experiência que lentamente se desenvolve dentro de cada um de nós. Estas perguntas vầo dirigindo o estudo.

Aconselhamos que você não as responda apenas uma vez; volte para atrás de vez em quando. Se vocé ao voltar, der uma resposta diferente, é sinal que vocè está utilizando o livro plenamente.

Hoje em dia há a necessidade de uma visão-contacto que só a museologia simples, adaptada à realidade do mundo atual, levará ao encontro e à conquista da dimensão do homem a que o museu se destina e às técnicas a serem equacionadas para aquele museu.

Se o museu atual deve representar uma resposta concreta para as várias dúvidas de diversos campos através do diálogo de suas coleções, estejam elas em exposição ou em reserva técnica, não podemos esquecer do mecanismo que o museu necessita para sua sobrevivência e, é ai que está o trabalho do museólogo: na documentação, na classificação, na leitura museológica, na pesquisa, na manutenção e conservação das coleções, no planejamento das exposiçōes, na cooperacão de apoio à ação educativa e cultural integrada, bem como na pianificação de novos museus. Enfim em todos os campos de ação da museologia atual.

A interdisciplinaridade dos museus é uma constante e faz parte de uma procura de equilibrio e da obrigaçáo de apoio técnico especializado em muitas áreas, porém não podemos com isso permitir uma intromissão, que hoje é frequente, e pode se dizer mesmo obsessi. va de especialistas de outras áreas na museologia. Educadores, pesquisadores de ciência, e de história, bem como arquitetos, economistas, críticos de arte, estatísticos, psicólogos, terão sempre seu lugar nos museus, porém sempre conduzidos pelos museólogos, que formam a estrutura de base.

Este Caderno de Exercícios, o primeiro de uma série, busca, através da reflexão e da prática, o encontro da museologia viva.

Fernanda de Camargo e Almeida e

Lourdes Maria Martins do Rego Novaes

Rio de Janeiro, 27 de novembro de 1976

Figura 3 - Texło introdutório do livro Introdução ao ensino dirigido de museologia. ${ }^{20}$ 
21. Id. (2010, p. 45-46).

22. Id. (1977, p. 11, grifo das autoras)
Lendo o livro é possível perceber que há um espaço - ainda que secundário - para refletir sobre a função dos museus na sociedade. $\bigcirc$ atendimento ao público se coloca como ação educativa dos museus, mas voltada àqueles que vão até a instituição. Não se problematiza o quanto a memória e a identidade desse público estão representadas na coleção, nem sua participação mais ativa na construção das narrativas dos museus.

Como agentes do campo internacional no Brasil, as autoras estavam bastante cientes das críticas que estavam sendo feitas à instituição "museu" nos anos 1960 e 1970, fora do Brasil. O tom comedido do seu texto - desse e de demais documentos saídos do Comitê Brasileiro -, além de ter relação com a sua tradição de formação, pode também expressar o receio que tinham das represálias do campo ao suposto engajamento político. Segundo o depoimento das museólogas e as evidências documentais, esse não era um temor infundado. Em 1971, depois de participar da Conferência Internacional do lcom em Grenoble, na França, Fernanda de Camargo Moro foi denunciada (Figura 4). Conforme ela mesma explicita, aderiu ao "Manifesto de Grenoble", cujo sentido não foi compreendido pela outra representante brasileira, que fez a denúncia. ${ }^{21}$ As fontes deixam entrever que ela foi acusada de ter feito críticas à condição política do país, que caminhava para o acirramento da ditadura civil-militar. Mais uma evidência da importância dada ao fato é que, de volta ao Brasil, ela foi demitida do quadro docente do Curso de Museus.

Essa conduta moderada também foi adotada pelo lcom-BR nos anos 1980, ainda sob a direção de Fernanda Moro e Lourdes Novaes, que selecionavam os conteúdos a serem replicados nas atividades nacionais. $\bigcirc$ reforço de uma perspectiva conservadora também se fazia em paralelo, sendo esta fortemente marcada pela defesa do monopólio da ação profissional do museólogo, conforme o texto de abertura do livro Introdução ao ensino dirigido de museologia deixa entrever:

A interdisciplinaridade dos museus é uma constante e faz parte de uma procura de equilíbrio e da obrigação de apoio técnico especializado em muitas áreas, porém não podemos com isso permitir uma intromissão, que hoje é frequente, e pode se dizer mesmo obsessiva de especialistas de outras áreas na museologia. Educadores, pesquisadores de ciência, e de história, bem como arquitetos, economistas, críticos de arte, estatísticos, psicólogos, terão sempre seu lugar nos museus, porém sempre conduzidos pelos museólogos, que formam a estrutura de base. ${ }^{22}$ 
Lisboa, 28/8/72

\author{
Exm?2. Senhor \\ Dr. Renato Soeiro \\ Director do Departamento \\ de Assuntos Cultura1s
}

Meu Exmo. Amigo

A pedido da Srâ. D. Fernanda Camargo, com quem estive o ano passado na Assembleia Geral do ICOM, em Grenoble, venho comunicar que, tendo assistido a todas as reuniores em que a Sra . D. Fernanda Camargo tomou a palavra, nada the ouvi dizer que possa ser conside rado como um ataque à política do governo brasileiro e, em meu en

- tender, é uma verdadeira calúnia afirmar o contrário.

Enviando saudosas lembranças para todos os amigos do DPHAN pe ço-lhe, Dr. Renato Soelro, que aceite os meus cumprimentos e protes tos de elevada consideragão.

A Directora do Museu

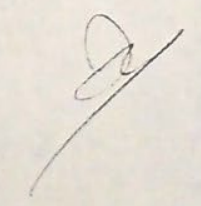

Maria José de Mendonça

Figura 4 - Carta de Maria José de Mendonça para Renato Soeiro a respeito de Fernanda de Camargo Moro, em 1972. Fonte: Mendonça (1972). 
23. Cf. Coelho (2015).

24. Em 1984 a profissão foi regulamentada pela Lei $\mathrm{n}^{\circ}$ 7.287 , cujo decreto de regulamentação foi assinado em 1985. Cf. Brasil (1984).

25. Bourdieu, op. cit.

26. Determinados balizamentos do campo museológico precisaram (e seguem precisando) da legitimidade dada pelo campo político, a exemplo da citada lei de regulamentação da profissão e do Estatuto de Museus - Lei $\mathrm{n}^{\circ} \mathbf{1 1 . 9 0 4}$, de 14 de janeiro de 2009 (Brasil, 2009). Do campo do patrimônio os museus tomaram emprestado, em grande medida, o sentido de preservação de bens culturais. Observa-se também, por exemplo, a inexistência de menção aos museus nas Constituições Federais até aqui. O sentido de preservação explícito na Carta Magna de 1988 está atrelado ao patrimônio, e o correspondente institucional deste - para a execução das políticas patrimoniais em questão - era o Instituto do Patrimônio Histórico e Artístico Nacional (Iphan), em suas diversas denominações. Cf. Gouveia, op. cit.

27. Cf. Bourdieu, op. cit.

\section{A REGULAÇÃO DAS RELAÇÕES}

A regulamentação da profissão é um tema à parte da constituição do campo museológico no Brasil e capítulo considerável da trajetória de Waldisa. As designações "profissionais de museus" e "museólogos" se confundiam e se distinguiam, ao passo que a museologia deixava de ser pensada enquanto conhecimento aplicado a museus para se organizar enquanto uma área do conhecimento. $\bigcirc$ desejo de intervir na afirmação legal do exercício da museologia fez com que as instituições debatessem seus espaços de atuação, correspondendo-se, fazendo declarações públicas, seminários nacionais e projetos de lei para a regulamentação. ${ }^{23}$ Defenderam as posições que ocupavam, manifestando-se a respeito do perfil ideal de profissionais e de museus para o campo. A regulamentação da profissão (pleiteada desde 1963 e efetivada entre 1984 e 1985), ${ }^{24}$ mais do que reger a relação entre formação e atividade laboral, teve a função de demarcar o que (discursivamente) se queria ou não como parte do campo.

De acordo com a perspectiva bourdieuana, a autonomização é um processo de expansão e retração. ${ }^{25}$ Concretamente, pode resultar no aumento de instituições e sujeitos implicados, mas também no aumento do controle quanto à participação desses agentes. Ao mesmo tempo que o campo busca ser detentor de suas decisões, não pode prescindir da negociação com outros campos, inclusive alguns que exercem influência sobre ele, como nesse caso se passa com o campo do patrimônio e o campo político. ${ }^{26} \mathrm{~A}$ autonomização não é algo positivo em si ou um processo natural para o qual se deve convergir. Tem relação com a especialização de um campo, mas na mesma proporção pode significar um distanciamento deste com relação às questões da vida social corrente, no presente, dissimulando uma atemporalidade do conhecimento produzido. Voltados ao jogo interno, os agentes investem seus esforços nas disputas entre si e na manutenção de suas posições dominantes, tanto quanto ou mais do que nos objetivos aparentes da produção do conhecimento em questão. ${ }^{27}$ Parece ter sido essa a direção que o campo museológico privilegiou nos anos 1980.

Waldisa Rússio atuou direta e indiretamente no processo de regulamentação da profissão de museólogo(a). Por sua iniciativa - seguida majoritariamente por sua rede de relações em São Paulo - foi criada a Associação Paulista de Museólogos (Asspam). Por meio dessa instituição ela encampou debates sobre as competências do profissional da museologia e, além disso, mobilizou medidas práticas para fazer o trâmite da regulamentação correr no Legislativo nacional (na imperativa relação com o campo político-jurídico). Nesse decurso, os agentes da área se dividiram em no mínimo duas posições: uma parte defendia que a formação para habilitar o 
museólogo era exclusivamente a graduação; e a outra, representada por Waldisa e pela Asspam, incluía também a pós-graduação. ${ }^{28}$ As defesas quanto a essas diferentes posições reafirmavam quais eram os saberes fundamentais para a lida com a preservação. Waldisa, que até acreditava que o museólogo era um vocacionado, defendia que esse sujeito deveria ser um trabalhador social. Essa noção, tomada de Paulo Freire e, segundo ela, também de Florestan Fernandes, exprime um exercício profissional consciente, que trabalha para a mudança. ${ }^{29}$ Com esse debate, Waldisa protagonizou a disputa para que os museólogos tivessem uma formação dentro da área das ciências sociais e humanas. Confrontando a posição majoritariamente defendida, que restringia a qualificação de museólogo à graduação, a campanha de São Paulo teve êxito, e o projeto de regulamentação aprovado admitiu também o mestrado e o doutorado como níveis de formação aceitos.

É válido recordar que a crítica aos museus e a ampliação do debate a respeito das suas funções tiveram expressão dentro e fora do campo museológico internacional. Dão evidência disso os temas debatidos na já citada Conferência de Grenoble, a formulação da ideia de ecomuseu em 1971, a realização do encontro em Santiago do Chile, em 1972 (legando a Carta de Santiago), e a criação do Movimento Internacional da Nova Museologia em 1984. No Brasil, a repercussão desse assunto nos anos 1970 e 1980 ficou restrita a alguns poucos agentes e discreta no discurso das instituições. A dimensão reflexiva sobre o que, por que, com quem e para quem se deveria preservar estava na periferia dos assuntos, conformando, segundo considero, uma espécie de paradigma emergente.

Segundo as evidências, um dos primeiros agentes a vocalizar a questão de dentro do campo museológico foi Ulpiano T. Bezerra de Meneses, com quem Waldisa Rússio estava em diálogo. Esse intelectual paulistano já era ouvido como referência nos anos em questão. Em 1975, estando à frente do Museu de Arqueologia e Etnologia da Universidade de São Paulo (USP), Ulpiano conduziu um dos debates do I Encontro Nacional de Dirigentes de Museus, realizado na Fundação Joaquim Nabuco (Recife, PE) - evento que também contou com a participação de Aloísio Magalhães e Gilberto Freyre. Na ocasião, afirmou:

Dificilmente se negaria, hoje, o conceito largamente difundido nos meios museológicos, inclusive em documentos oficiais, de que o museu, instituição a serviço da sociedade, deve ser emanação dessa mesma sociedade. Entretanto, o confronto do princípio com a situação efetiva, no Brasil como em outros países, revela certo descompasso que torna explicável a crise por que vem passando, nestes últimos dez anos, em todo o mundo, não só os museus enquanto instituição, como o próprio conceito de museus. ${ }^{30}$
28. Cf. Coelho, op. cit.

29. Cf. Rússio (2010b, p. 153).

30. Meneses (1975, p. 1). Texto que subsidiou os debates do grupo de trabalho $n^{\circ} 7$ no I Encontro de Dirigentes de Museus. 
31. Ibid., p. 2.

32. Ibid., p. 3.

33. Cf. Instituto Joaquim Nabuco de Pesquisas Sociais (1976).
Meneses foi convidado a lançar os pontos de debate sobre o museu e o meio. Atento à alteração das funções museais, ele sugeriu - possivelmente inspirado no canadense Duncan Cameron - que a instituição deveria ser menos "templo" e mais "fórum". Ou seja, menos espaço de sacralização dos objetos e mais lócus de debate a respeito da memória e da representação. Ulpiano indagou: "teriam os museus o direito de excluir certos aspectos negativos ou menos tranquilizantes da realidade que, como todo organismo vivo, tem sua história patológica e guarda o traço de suas cicatrizes?". ${ }^{31}$ Afirmou ainda que era simplista dizer que a instituição estava a serviço da comunidade, quando na prática um "grande número de museus funciona como corpus alheios às comunidades em que se inserem". ${ }^{32}$

Apesar de serem contemporâneos, no contexto dos anos 1970, Waldisa e Ulpiano ocupavam lugares distintos no campo museológico. Essa diferença está marcada por muitos aspectos difíceis de serem objetivados, mas também por dois elementos fundamentais quando se pensa em suas trajetórias: as condições de classe e de gênero. Ainda que não seja o tema aqui, é oportuno evidenciar que a carreira das mulheres estava (e em certa medida ainda está) restrita a certos postos, temas e disposições. Enquanto os homens eram considerados doutores, detentores dos conhecimentos mais valorizados, as mulheres eram as "donas", identificadas com um saber técnico, acessório, relativo aos cuidados e ao ambiente doméstico.

A assimetria entre os gêneros pode ser observada por meio do evento anteriormente referido da Fundação Joaquim Nabuco, em 1975. A ocasião tem grande relevância, pois seu objetivo era formular bases para uma política museológica, num ensejo pioneiro na área até então. ${ }^{33}$ Vale notar, no entanto, que todos os convidados a falar eram homens dirigentes na administração pública e diretores daqueles que eram considerados os principais museus do país. Observando os documentos que marcam a preparação para o encontro e seus registros, nota-se a quase inexistência de mulheres nas comissões e nas comunicações. A exceção - que confirma a regra - é a participação da museóloga do Museu de Arte Didática de Natal na condição de "secretário" da comissão. Considerando a histórica segregação do pensamento feminino, vale indagar: até que ponto às mulheres era facultado pensar politicamente e pensar politicamente os museus? Os museus considerados influentes para a interlocução sobre política pública eram dirigidos somente por homens? São questões relevantes que podem dizer sobre o afastamento da museologia com relação aos temas políticos, se levarmos em conta a predominância numérica das mulheres no campo.

Nos anos 1980, Waldisa Rússio alcançou a condição de doutora, de autoridade a ser ouvida na museologia paulista, com expressão na interlocução nacional, ainda que também fosse criticada. Seus embates explíititos, documentados, 
se deram em torno de vários temas: a crítica à visão barroseana de museus; a centralização e falta de capilaridade nas atividades do lcom-BR e da ABM; e o trato supostamente discriminatório que essas instituições dispensavam aos egressos do Curso de São Paulo. Confrontando a tradição instituída, portanto, Waldisa Rússio aportou capitais simbólicos trazidos de fora do campo museológico, mas muito valorizados dentro dele. Havia se formado em Direito pela USP /carreira e formação muito reconhecidas); cursou mestrado e doutorado; tinha experiência de atuação prática e interlocução internacional, entre outros aspectos.

A paulistana iniciou sua ałuação na administração pública do estado de São Paulo em 1957. Na década de 1980 havia firmado uma carreira ascendente, com atuação em postos decisórios, diretamente ligados ao primeiro escalão da administração. Em 1967 ela participou do Grupo Executivo da Reforma Administrativa do Estado em São Paulo, que, entre outras coisas, resultou na criação da Secretaria de Cultura, Esporte e Turismo e do Conselho de Defesa do Patrimônio Histórico, Arqueológico, Artístico e Turístico (Condephaat). Também nesse contexto foram criados o Museu da Casa Brasileira, o Paço das Artes e o Museu de Arte Sacra. Outro destaque de sua carreira na administração pública foi a participação no Grupo Técnico de Museus, que pesquisou as instituições do estado e possivelmente ocasionou que ela conhecesse todas in loco. ${ }^{34}$

Depois de quinze anos de graduada, Waldisa voltou aos estudos formais para o mestrado, seguido do doutorado, ambos na Fundação Escola de Sociologia e Política (Fesp). Isso trouxe um incremento considerável ao seu capital simbólico, pois tal nível de formação era raro entre os profissionais no campo. Nos dois trabalhos de pós-graduação a museóloga fez análises sobre os museus de São Paulo, do Brasil e do mundo. Particularmente, na tese acrescentou também o planejamento do pretenso Museu da Indústria. ${ }^{35}$ Criou assim conteúdo para publicações que fez e divulgou, especialmente nos anos 1980. Waldisa estruturou sua interlocução nacional e internacional estrategicamente, quando, por exemplo, convidou Fernanda de Camargo Moro (que seguia à frente do lcom-BR) para suas bancas de mestrado e doutorado. Com isso, assegurou a leitura de ambas as pesquisas, comunicando sua visão a respeito dos museus e explicitando sua discordância com a matriz do pensamento no Rio de Janeiro, o que também se dirigiu ao próprio Comitê. Além disso, esse contexto foi oportuno para pôr em prática um planejamento anterior de criar um curso de formação em São Paulo. Isso aconteceu logo após a conclusão do mestrado, na mesma Fesp, em parceria inicial com o Museu de Arte de São Paulo Assis Chateaubriand. ${ }^{36}$ A partir daí, Waldisa assumiu a direção do curso, com lugar de destaque na seleção dos conteúdos, e se tornou professora de museologia,
34. Cf. Coutinho (2010, p. 23).

35. Waldisa Rússio projetou e articulou a fundação do Museu da Indústria. Tendo sido criado por ato legal, ainda que não tenha disposto de sede, equipe e de um corpo para funcionar, isso possibilitou que ela desempenhasse algumas atividades como criadora e diretora da instituição (Bruno, 2010c; Gouveia, op. cit.).

36. Cf. Araujo (2010, p. 109). 
37. Carvalho (2017).

38. Rússio (1981).

39. Cf. Duarte Cândido (2003); Santos (2002); Soares; Carvalho; Cruz (2014).

40. Rússio (2010d, p. 127, grifo nosso).

41. Rússio (1984a).

42. Ibid. ocupando posição relevante na formação de uma geração de museólogos, entre 1977 e 1990 (ano de seu falecimento).

A interlocução com agentes do campo internacional também conferiu prestígio e oportunidades a sua trajetória. Foi oportuno, por exemplo, o espaço para pensar teoricamente a museologia, unindo-se a outros sujeitos que aderiam a essa frente, por meio do Comitê Internacional de Museologia (lcofom/lcom), criado em 1977. ${ }^{37} \mathrm{Em}$ 1981, juntamente com os principais debatedores do campo internacional, Waldisa publicou no Icom a sua perspectiva sobre o estatuto científico da museologia. ${ }^{38}$

Na percepção de diferentes autoras e autores, ${ }^{39}$ foi Waldisa Rússio quem iniciou no Brasil o esforço de teorização da museologia e, ao longo da década de 1980, foi a única a fazêto, mesmo considerando a participação de outras brasileiras no Icofom. Importa observar que, no cerne de sua definição teórica, que se ocupa de circunscrever um objeto geral para a museologia, está também uma forte dimensão da atuação prática. Isso contraria uma falsa dicotomia entre teoria e empiria, comum a diversas áreas e também à museologia. Mesmo pensando a museologia como um conhecimento que extrapola os museus, Waldisa destacou a necessidade de diálogo da teoria com a realidade concreta dessas instituições. Além disso, ainda que buscasse uma síntese explicativa para estruturar esse conhecimento, Waldisa achou espaço para destacar o poder e a capacidade de ação dos sujeitos. Cito-a:

[...] o objeto da museologia é o fato museal ou fato museológico... O fato museal é a relação profunda entre o homem, sujeito conhecedor, e o objeto, parte da realidade à qual o homem igualmente pertence e sobre a qual tem o poder de agir. ${ }^{40}$

Em texto manuscrito, que está sob a guarda do Arquivo do IEB, ${ }^{41}$ Waldisa explica que o cenário "institucionalizado" onde ocorre o fato museológico deve ser "reconhecido não apenas por quem o cria ou estabelece, mas reconhecido também - e sobretudo - pela comunidade de que emerge e à qual se deve destinar prioritariamente". Diante dessa constatação e analisando os museus dos anos 1980, afirma: "bem poucos museus o são verdadeiramente e podem, em termos científicos, ter cenários condicionadores do fato museológico". ${ }^{42}$ Retomando o ponto abordado, trata-se então de uma formulação teórica com base e correspondência numa realidade concreta, socialmente situada. Na perspectiva de Waldisa, portanto, o objeto da museologia não existe isolado, de modo abstrato, como algo em si; mas há certas condições para que se realize. Estas levam em conta o poder de ação do homem sobre aquilo que será musealizado (o objeto), e tal poder de agir é o que pode ocasionar ou não o fato museológico. 
A inserção de Waldisa Rússio na elaboração teórica da museologia - algo que também deve tê-la favorecido para uma visão sistêmica - foi marcada pela experiência de integrar o grupo de elaboração do Dictionarium museologicum, que visava à definição de terminologias de interesse para o campo, em várias línguas. Em razão desse Dictionarium, Waldisa viajou a Veszprém (Hungria) regularmente entre os anos de 1983 e 1986 para participar de reuniões de trabalho. Complementarmente, em suas passagens pela Europa, visitava museus, se reunia com outros agentes, ministrava e participava de cursos, além de trocar material escrito. $\bigcirc$ Dictionarium foi lançado em 1986 e teve baixa repercussão no Brasil, seja porque foram poucos os exemplares que circularam, ou ainda porque houvesse divergência com outros agentes daqui sobre a autoridade que Waldisa exerceu ao elaborar os verbetes. ${ }^{43}$

A repetição de uma ideia é uma estratégia na relação entre os agentes na elaboração do conhecimento. Grosso modo, a formação de conceitos e noções depende menos da qualidade explicativa destes e mais da força de adesão que encontram entre os pares. Uma noção em construção, como era o caso do objeto da museologia, estava amparada na possibilidade de assentimento que era capaz de angariar. A formulação teórica constitui um momento recorrente no processo de autonomização dos campos. Estruturar esse conhecimento viabiliza a reprodução de uma noção sintética, concentrada de sentido. Ao se estabelecer consenso sobre o que é a museologia, busca-se definir qual é seu corpus de atuação, apontar o que está dentro e o que está fora de sua área de interesse. Na década de 1970, portanto, era importante estimular que alguns agentes consagrados ("com+sagrado") se dedicassem a essa tarefa e que essas sínteses passassem a ser difundidas, especialmente a partir das posições de formação. O capital simbólico gerado com a teoria precisava alcançar seus clientes, e Waldisa Rússio se aplicou nisso, comunicando repetidamente a definição de "fato museológico" e empenhando-se na distribuição de seus textos.

No jogo dos campos científicos existe uma supervalorização da posição de produção teórica, como se fosse um conhecimento mais especializado e essencial. Nessa medida, consagrar uma definição é consagrar-se a si mesmo. Nas duas décadas que se seguiram à morte prematura da museóloga - anos 1990 e 2000 -, fora de São Paulo e da Bahia, a referência (discreta) a sua trajetória se fez em razão do "fato museológico". Antes de 2010 (tendo sido a publicação organizada por Maria Cristina Oliveira Bruno um divisor de águas), ${ }^{44}$ pouco repercutiam outros aspectos de sua trajetória, e é raro que se tenha valorizado a dimensão política e social de sua produção. Em certa medida, isso também deixa entrever que não foram essas as características que o campo quis destacar.

A partir desse lugar de consagração, mas também como uma mulher da classe trabalhadora, Waldisa Rússio ministrava os conteúdos da museologia teórica
43. Houve desacordo manifesto entre o Icom-BR e Waldisa Rússio quanto ao Dictionarium museologicum. A esse respeito pode-se consultar: Éri (1985); Associação Paulista de Museólogos (1985a).

44. Cf. Bruno (2010b, 2010c). 
45. Arruda (1986)

46. Superintendência de Museus de Minas Gerais (1985).
Quadro 1 - Curso Museologia Popular na Bahia, de 19 a 23 de outubro de 1984. Fonte: Rússio (1984b). e científica no curso da Fesp e debatia o sentido dos museus. Ao mesmo tempo, participava da criação do Museu do Bixiga, em São Paulo, junto com as lideranças comunitárias do bairro, dava assessoria à criação de novos museus, mantinha seu trabalho cotidiano na administração pública e participava de cursos e eventos pelo Brasil. Um desses se chamou Museologia Popular e teve edições na Bahia, em 1984, e em 1986 no Pará ${ }^{5}$ e em Belo Horizonte. ${ }^{46}$

A programação do curso ministrado na Bahia, transcrita no Quadro 1, exemplifica alguns dos temas tratados:

\begin{tabular}{|c|}
\hline $1^{\circ}$ dia \\
\hline Museologia e Museu; \\
\hline Desenvolvimento da ciência e da prática museológica; \\
\hline A instituição museal; \\
\hline O museu como cenário da relação homem × objeto (realidade); \\
\hline O museu como instrumento e linguagem de poder; \\
\hline Museologia hoje, Museu, hoje. Ecomuseu e ecomuseologia. \\
\hline $2^{\circ}$ dia \\
\hline Cultura e política cultural; políticas museológicas; \\
\hline Paternalismo e autogestão; "pacotes culturais" e ação comunitária; \\
\hline Identidade cultural; \\
\hline Comunidade; \\
\hline Consciências: crítica e mágica; consciência possível. \\
\hline $3^{\circ}$ dia \\
\hline
\end{tabular}

Reconhecimento da comunidade. $\bigcirc$ museu enquanto instituição e enquanto "comunidade" ou parte da comunidade. Interações;

A museologia popular e seus métodos de trabalho: pesquisa/coleta e coleções/documentação/ conservação/comunicação. Pressupostos éticos. Métodos, estímulo e intervenção. O território e a comunidade. O patrimônio cultural. A população e os "públicos".

\section{$4^{\circ}$ dia}

As exigências da Museologia Nova (Popular) e da Nova Museologia;

Os agentes da memória dinâmica;

O homem, sujeito e objeto da pesquisa e da História; questões práticas. A adequação dialética entre teoria e prática museológica e os trabalhos com memória social.

\section{$5^{\circ}$ dia}

A múltipla "realidade brasileira" e as possibilidades efetivas de utilização de uma Museologia Popular;

Papel do museólogo. Ampliação do cenário museológico e do campo de trabalho. 
Os subtemas desse curso refletem alguns dos principais interesses de Waldisa. Com a divulgação desse conteúdo, ela falava de dentro do campo, voltada para dentro, mas com um olhar que extrapolava as suas supostas fronteiras. ${ }^{47} \mathrm{Na}$ bibliografia ela recomendava seus próprios textos, além de Hugues de Varine, Gaël de Guichen, Antonio Augusto Arantes e Ecléa Bosi. Indicava também a leitura de "toda a obra publicada" de Paulo Freire. ${ }^{48}$

\section{POLÍTICA MUSEOLÓGICA}

Uma das conclusões a que se pode facilmente chegar ao analisar a política museológica $^{49}$ no Brasil é que ela é muito recente. Apesar do número crescente de museus no país, sabemos que mesmo as instituições federais vinculadas ao Instituto do Patrimônio Histórico e Artístico Nacional (lphan) poucas vezes gozaram de ações sistemáticas e planejadas. $\bigcirc$ ensejo de criação de uma política museológica nos anos 1970 não parece ter tido correspondência com nenhuma ação concreta. Entre as fontes consultadas, há inúmeros exemplos de reclamações do setor, registrando o descontentamento com os recursos investidos. Ainda assim, as críticas são pontuais e raramente cobram de modo incisivo a criação de um planejamento de Estado para a cultura e para os museus. A conservação das coleções, sob o ponto de vista material, segue sendo a justificativa elencada para a valorização dos museus e dos museólogos.

Diferentemente do que se passava no campo museológico, o campo do patrimônio foi atravessado pelas tensões sociais dos anos 1970 e 1980. Analisando essas transformações, Marly Rodrigues pontua que em São Paulo, na segunda metade da década de 1970, o discurso em prol da preservação teve ampla repercussão social. $\bigcirc$ patrimônio passou a ser tema debatido publicamente, a partir do estímulo da mídia. Segundo a autora, para desempenhar suas funções, - Condephaat precisou dialogar com associações preservacionistas, a exemplo da Associação de Defesa do Patrimônio da Comunidade. ${ }^{50}$

Como compartilhava desse ambiente, Waldisa Rússio transpôs essa atmosfera para a museologia. Ela defendia, por exemplo, a necessidade de que as pessoas diretamente implicadas com a representação cultural e histórica das instituições museais fossem consultadas em primeira hora no caso da criação de novos museus. Vejamos:
47. De acordo com a teoria bourdieuana, os limites de um campo não são fixos ou pré-determinados, pois são objeto de disputa do próprio campo (Bourdieu, op. cit.). Ou seja, está em disputa, por exemplo, a autoridade para definir os temas fundamentais do campo, e isso, consequentemente, vincula agentes e suas posições. Afirmo o dentro e o fora do campo museológico referindo-me àquilo que está no centro do debate entre os agentes e aquilo que não está, considerando a relação entre os agentes, seus interesses e suas posições nos anos 1970 e 1980. Um exemplo: museólogas(os) e outras(os) trabalhadoras(es) de museus estavam (e estão) inegavelmente dentro do campo, ao passo que indivíduos da sociedade civil (que não têm um saber especializado a respeito do contexto técnico da preservação), mesmo que tenham interesses vinculados a um bem cultural, podem ser considerados pessoas de fora do campo, de acordo com a posição do agente que tem mais poder para forjar as fronteiras.

48. Rússio (1984b).

49. Considero a política museológica como uma pactuação formal entre o Estado e a sociedade civil a respeito dos critérios e das condições de exercício das funções museais, expressa por meio de planejamentos, programas, leis e outros marcos legais, dotação orçamentária etc.

50. Rodrigues (2000).
[...] achamos que o museu resulta da comunidade, e é tempo de fazer museu com a comunidade e não para a comunidade. 
51. Rússio (1984c, p. 60, p. 88).

52. Rodrigues, op. cit., p. 92.

53. Ibid. $[\ldots]$

Durante muito tempo se preservou com os conceitos de uma determinada classe, pretendendo que a maioria aceitasse esses conceitos, o que, realmente, não é possível; então, a preservação não tem autenticidade exatamente porque ela não é resultado técnico de um trabalho comunitário, ela não é o resultado político de uma ação social. Realmente aqui reside todo o erro que até hoje nós temos notado, ou pelo menos o erro principal, o mais grave, nas atitudes, nos mecanismos da política de preservação, nos mecanismos da política museológica. Aliás, política não existe ou, talvez, existindo uma política, seja exatamente uma política para se preservar o status quo, e conduzir toda a sociedade com uma leitura do passado, de um passado hermético de uma classe social. Acho que está no momento de recuperarmos essa dinâmica cultural, essa dinâmica do social, acreditar no processo de abertura que se anuncia e conquistá-la a cada dia. Acho que a memória, preservação, musealização são atos políticos e temos de assumi-los como tal, e são atos e espaços de conquista e não dádivas de ninguém. Só podem realmente fazer museus autênticos na medida em que eles se inspirem na comunidade. ${ }^{51}$

Essas palavras foram ditas durante a participação da museóloga no Seminário Cultura, Patrimônio e Preservação, organizado pelo Condephaat. Rodrigues destaca que esse evento teve relevância no aprofundamento do debate do conceito de patrimônio, sendo importante inclusive para a qualificação do pessoal técnico do próprio órgão. ${ }^{52}$ A primeira etapa do Seminário de 1983 (e o livro que o registra) tratou principalmente dos temas "Cultura, Patrimônio e Preservação", "Identidade Cultural" e "História e Poder Local". Waldisa apresentou contribuições ao primeiro dos temas e ressaltou a importância do debate interdisciplinar. Falou marcadamente a partir do campo museológico, afirmando que seu intuito era evidenciar alguns dos conceitos, "dados e elementos culturais" com os quais os museólogos operavam.

No trecho em destaque, Waldisa explicitou a ausência de uma políica museológica. Por sua trajetória profissional, e particularmente pela interlocução no cenário cultural paulista, sua perspectiva de política museológica não era apenas discursiva. Quando ela afirmava a necessidade de participação da comunidade, pensava na realização de assembleias públicas, cursos abertos, reuniões, consultas, instrumentos e mecanismos de participação - léxico próprio do contexto político de abertura dos anos 1980, que se afirmava no repertório das políticas de patrimônio em São Paulo. ${ }^{53} \mathrm{O}$ tema não era novo para ela, pois desde a década anterior vinha sendo insistente, no diálogo com a Secretaria de Estado de Cultura, quanto à necessidade de construção de uma políitica cultural e, especificamente, de uma políitica museológica. Em 1974, Waldisa abordou a questão defendendo um "sistema museológico". Na ocasião de um seminário na Casa Brasileira, ela indagou quais eram os "grupos socioeconômicos" beneficiados com as atividades culturais. Enfatizou também que a 
ação do Estado na cultura deveria se dar como parte dos serviços públicos a serem prestados e que, para isso, deveriam ser assegurados certos parâmetros. ${ }^{54}$

Em março de 1983, como representante da Associação de Trabalhadores de Museus (ATM), Waldisa escreveu ao secretário de Cultura para reivindicar a formulação da política cultural e museológica. Meses depois, representando a ATM e a Asspam, criticou fortemente a edição do Decreto $n^{\circ} 20.955$, de $1^{\circ}$ de junho de 1983, que interferia na estrutura da Secretaria de Cultura do Estado. No ano seguinte, a preocupação com uma legislação que melhor amparasse o patrimônio e os museus foi tema de destaque do $1^{\circ}$ Seminário Internacional de Legislação Comparada no Setor de Cultura. A museóloga participou do evento, com oportunidade de fala, apresentando suas indagações, seu diagnóstico da questão e o que considerava serem os pontos mais urgentes. ${ }^{55}$

Uma ocasião excepcional nas articulações do campo se deu em 1985, quando a Asspam, o lcom-BR e a Associação de Museólogos da Bahia entregaram uma carta conjunta ao recém-criado Ministério da Cultura. ${ }^{56}$ A carta foi construída em reunião da Asspam, que repercutia o tema com frequência em suas assembleias. $\bigcirc$ documento afirmou os mesmos princípios gerais das falas anteriores de Waldisa. Reivindicou-se uma política cultural e museológica que partisse da escuta dos segmentos profissionais e artísticos e da sociedade como um todo. A primeira parte do documento apontou críticas à situação dos museus, reclamou da falta de critérios para a criação de instituições novas e da falta de verba para a manutenção das já existentes. Observou-se que na maior parte das vezes os museus serviam apenas aos turistas e a uma "elite intelectualizada". Criticou-se a falta de cursos de formação, a falta de observação de parâmetros técnicos no trato do acervo e a forma como ocorria a nomeação de diretores. Afirmou-se que, nas condições em que estavam, os museus deixavam de cumprir seu principal objetivo: "a atuação dinâmica junto à sociedade". Além das críticas, formularam-se sugestões que exprimiam o mesmo sentido: dotar os museus das condições técnicas adequadas, por meio de profissionais qualificados, que atuassem em prol da relação das instituições com a sociedade.

Em termos da estrutura pública federal para o campo museológico, na década de 1980 duas frentes foram criadas: o Programa Nacional de Museus e o Sistema Nacional de Museus. Segundo o Boletim do Sphan/Pró-Memória, ${ }^{57}$ o Programa Nacional, criado em 1982, tinha como objetivo "prestar assistência à totalidade do universo museológico", mas privilegiaria os museus ligados à Secretaria de Cultura do Ministério da Cultura, para depois prestar assistência aos demais que solicitassem. ${ }^{58}$ Com funções análogas, em 1986 foi criado o Sistema Nacional de Museus, por meio do qual se esperava uma articulação entre os estados para uma atuação coordenada da área. Na prática, o órgão teve uma função normativa com relação aos museus e
54. Rússio (2010b, p. 59).

55. Rússio. $1^{\circ}$ Seminário Internacional de Legislação Comparada no Setor de Cultura [1984]. In: Bruno (2010b, p. 160).

56. Associação Paulista de Museólogos (1985b). A carta foi posteriormente publicada em Bruno (2010b). Na mesma ocasião foi entregue uma carta ao Conselho Nacional de Desenvolvimento Científico e Tecnológico (CNPq), assinada pelas mesmas instituições, também com o intuito de solicitar investimentos no campo museológico.

57. Boletim Sphan/Pró-Memória (1982).

58. Ibid. 
59. Cf. Coutinho (2017) apud Gouveia, op. cit., p. 308-309.

60. Cf. Chagas (2017) apud Gouveia, op. cit., p. 375-376.

61. Rússio (2010a, p. 167) visava descentralizar recursos, especialmente financeiros. Para cumprir esse objetivo, foi impulsionada a criação dos sistemas estaduais de museus. ${ }^{59}$ As funções do Programa e do Sistema se sombrearam e tiveram, conforme apurado, pouco alcance. Também, em nenhum dos dois casos havia o objetivo de desenvolver uma política museológica. ${ }^{60}$ Importa frisar, no entanto, que mesmo diante dessas limitações, os agentes que acompanharam as ações do Sistema Nacional de perto afirmam que estas foram essenciais para o fortalecimento da relação entre os museus e para dar uma visão de conjunto às instituições nacionais. Deste modo, até onde se identificou, as iniciativas empreendidas por Waldisa Rússio e pelos agentes que a apoiaram foram o que de mais arrojado se fez para a elaboração de políticas museológicas nos anos 1980.

Enquanto o campo do patrimônio se abria para as demandas sociais e para outras áreas de conhecimento, o campo museológico buscava se fechar, mesmo com a agitada situação política do país em prol da redemocratização. A museologia waldisiana estava, no entanto, atravessada pelas condições sociais do presente. No texto "A difusão do patrimônio", Rússio indagou:

Que tempo vivemos nós, hoje, em nossa América sofrida?

Na maioria significativa de nossos países, é tempo de grandes distâncias sociais: grandes massas de camponeses sem terra, vagando errantes dentro de seus países; de operários sem acesso ao trabalho, ou sem segurança de mantê-lo; onde poucos chegam à universidade e, os que chegam e a concluem, não têm garantida sua ocupação; de quantidades de deficientes à margem de todo benefício social; de populações inteiras reduzidas à qualidade de "sub-raças" em todos os planos, desde o intelectual e físico em razão da fome contínua e congênita. Tudo isso em países paradisíacos, que seguem assim todavia ou que vão se destruindo por assentamentos humanos sem ordenação, equilíbrio e justiça para com os homens e a natureza.

Tempo em que seguimos com o etnocentrismo destrutivo dentro de nossos países mesmos, como se estrangeiros fôssemos! (e ai dos índios, dos "crioulos", dos negros e dos despossuídos!).

Tempo em que milhões de crianças estão abandonadas e soltas nas ruas... e crianças que não somente pedem mas que também são crianças que roubam e, às vezes, matam.

Que tempo é este, no qual se tem medo das crianças?

No rumo dos acontecimentos da década de 1980, a Assembleia Nacional Constituinte (ANC) acenava com uma possibilidade de alterar o fazer políticoadministrativo, a partir de uma nova compreensão de cultura e patrimônio. Houve nesse processo a participação direta de técnicos do Serviço do Patrimônio, intelectuais de diferentes campos do conhecimento e sociedade civil. Ou seja, um grupo difuso e ainda assim com capacidade de expressão e mobilização. Segundo Yussef Daibert 
Salomão de Campos, a redemocratização e a ANC não apontavam uma ruptura com as estruturas que sustentavam o regime militar, pois só foram possíveis diante da conciliação de setores conservadores e progressistas. Ainda conforme relembra o autor, fizeram parte da ANC, por exemplo, os "deputados biônicos" eleitos em 1982, no regime militar. Mas, mesmo diante de uma Constituinte, em parte conservadora, Campos evidencia que o discurso a respeito do patrimônio - quanto a representação, identidade, memória, direito e participação - causou poucas reações contrárias. $\bigcirc$ aspecto mais debatido em torno dos direitos culturais e que impactou vários outros pontos da Constituição dizia respeito à questão fundiária, de indígenas e quilombolas. Uma das poucas falas contrárias quanto ao papel do Estado na preservação foi a do então Senador Álvaro Valle, que defendeu a retirada do assunto do texto da lei, argumentando que não cabia à Constituição definir o que era patrimônio. ${ }^{62}$ Curiosamente, trata-se do mesmo parlamentar que apresentou o projeto de regulamentação da profissão de museólogo. Sua atitude talvez confirme que tanto ele como os demais agentes empenhados na regulamentação eram afeitos ao caráter técnico, ao passo que refutavam o caráter político do patrimônio.

\section{CONSIDERAÇÕES FINAIS}

Ao analisar o campo museológico por meio da trajetória de Waldisa, não se deseja usá-la como régua para medir a qualidade das ações dos outros agentes, seus contemporâneos. É importante ter clareza de que as posições em campo, sejam de reprodução ou transformação da ordem instituída, têm relação com muitos aspectos da ação dos agentes. Estes agem uns em relação aos outros, resguardando as suas posições, ao mesmo tempo que avaliam, objetiva ou subjetivamente, os capitais que podem lograr, inclusive no enfrentamento. Não se trata, assim, de tomar a atuação de Waldisa com uma perspectiva mítica, mas de compreender lespecialmente por meio dos embates que ela teve com outros agentes) onde o discurso do campo cindia, onde destoava e como refratava o todo social para se voltar a questões endógenas.

A respeito da compreensão da instituição "museu", Waldisa Rússio foi uma das agentes no campo que, nas décadas de 1970 e 1980, mais aderiv e atuou em favor de um paradigma social emergente no Brasil. A dimensão crítica quanto à função dos museus encontrou uma acolhida em sua forma de ver e pensar o mundo. Sua origem social e identificação com a classe trabalhadora - exceção no campo até pelo menos os anos 1970 -, sua formação no Largo de São Francisco, a carreira na administração pública, a influência da dimensão políitica em sua vida pessoal lo
62. Campos (2015, p. 140141). 
63. Isso pode ser observado em manifestações do campo, nos anos 1980 e seguintes, que elogiam as competências técnicas dos profissionais museólogos e, em nome dessas mesmas competências, justificam a necessidade de manutenção dos museus.

64. Brasil (2005, p. 16).

65. Conforme o slogan "Cultura é um bom negócio", do Ministério da Cultura no governo de Fernando Henrique Cardoso. que pode ser tratado em outras pesquisas e textos) e, muito provavelmente, a experiência da trajetória feminina influenciaram sua postura político-ideológica.

No contexto da "luta pela regulamentação", para a posição que orbitava em torno de Waldisa Rússio o importante era formar o agente trabalhador social, enquanto para os setores dominantes no campo o objetivo era formar o profissional técnico museólogo. Mesmo com o advento das questões teóricas da museologia, consideramos que o critério mais valorizado - recorrentemente defendido e objeto de distinção do profissional graduado, em oposição ao pós-graduado - seguiu atrelado à capacidade técnica para lidar com os aspectos materiais da preservação. ${ }^{63}$ Curiosamente também, mesmo após 1985, a defesa do profissional museólogo seguiu sendo um tema recorrente nos eventos realizados no campo.

Mesmo quando discursivamente o campo se alinhava com a função social dos museus e com o nascimento de uma museologia teórica, na prática investia seus capitais (simbólicos, tendo uma correspondência efetiva com recursos humanos e financeiros, por exemplo) na valorização de tradicionais conhecimentos técnicos. Isso, em parte, explica por que praticamente não houve participação do campo museológico nas ocasiões de reformulação conceitual da noção de cultura e de patrimônio. Analisando documentos que registram movimentos da área, é fácil perceber que havia um distanciamento de temas que pudessem ser considerados polêmicos. As questões técnicas que impactavam a guarda e a extroversão dos bens materiais foram também um mecanismo para o campo passar ao largo de assuntos que se impuseram na agenda do patrimônio. Temas considerados mais políticos, mesmo quando tratados, não apontavam uma direção e tampouco uma correspondência com a atuação prática da maior parte dos agentes. A questão da própria estruturação da carreira e da área, como campo de conhecimento e disciplina acadêmica, e a correspondência em termos de estrutura profissional administrativa, além das muitas querelas internas relativas a isso, ocuparam mais o tempo e o espaço das relações museológicas.

Em 2003, quando da elaboração da Políitica Nacional de Museus, indicou-se que o papel social das instituições era uma questão importante a ser tratada no planejamento para os anos seguintes. Essa valorização tem relação com os rumos políticos de então, mas também com o reconhecimento de que se tratava de um dos pontos fracos das instituições brasileiras. ${ }^{64}$ Esse contexto é herdeiro do acanhamento dos anos 1980 e da mudança de foco nos anos 1990, quando as políticas culturais voltaram à instabilidade e foram embaladas pelo discurso neoliberal como "um bom negócio".65

Relembrando um dos aspectos debatidos no referido seminário Democracia, Patrimônio e Direitos, os anos 1980 foram profícuos para o estabelecimento das 
bases das políticas nacionais e estaduais executadas de 2003 a 2015. Revisitar essa década é ainda mais importante no cenário atual, de descontinuidades e desfazimento das políticas de cultura e educação. Enquanto vemos atônitas(os) a radicalização na disputa de memória e verdade e as tentativas de cerceamento aos museus, devemos nos preparar para a próxima virada, quando poderemos construir, por dentro do campo museológico, políticas radicalmente mais participativas. Que a trajetória de Waldisa Rússio nos inspire, que a história do campo nos estimule a caminhar numa mesma direção, que Oxalá nos proteja e Exu nos aponte os caminhos! 


\section{REFERÊNCIAS}

FONTES MANUSCRITAS

RÚSSIO, Waldisa. [Caderno de notas]. Arquivo do Instituto de Estudos Brasileiros da Universidade de São Paulo, Fundo Waldisa Rússio, Caixa 002, Documento 01.0052. São Paulo: IEB, 1984a.

FONTES IMPRESSAS

ARRUDA, Euler Santos. [Correspondência]. Arquivo do Instituto de Estudos Brasileiros da Universidade de São Paulo, Fundo Waldisa Rússio, Caixa 087, Documento 18.0378. São Paulo: IEB, 1986.

ASSOCIAÇÃO PAULISTA DE MUSEÓlOGOS. [Correspondência da Asspam para o Comitê Consultivo do Icom]. Centro de Documentação da Fundação Escola de Sociologia e Política de São Paulo, Coleção Curso de Museologia, Caixa 02-06. São Paulo: Cedoc, 1985a.

ASSOCIAÇÃO PAULISTA DE MUSEÓlOGOS. [Ofício ao Ministério da Cultura]. Arquivo do Instituto de Estudos Brasileiros da Universidade de São Paulo, Fundo Waldisa Rússio, Caixa 085, Documento 18.0327. São Paulo: IEB, 1985 b.

BOLETIM SPHAN/PRÓ-MEMÓRIA. Brasília, DF: Fundação Nacional Pró-Memória, n. 20, set./ out. 1982.

ÉRI, István. [Correspondência para Teresa Gomes Ferreira]. Centro de Documentação da Fundação Escola de Sociologia e Política de São Paulo, Coleção Curso de Museologia, Caixa 02-06. São Paulo: Cedoc-Fesp, 1985.

MENDONÇA, Maria José de. [Correspondência]. Destinatário: Renato Soeiro. Núcleo de Memória da Museologia no Brasil, Coleção Fernanda de Camargo Moro. Rio de Janeiro: Unirio, 1972.

MENESES, Ulpiano T. Bezerra de. GT 7: relação do museu com o meio. Núcleo de Memória da Museologia no Brasil, Coleção Therezinha de Moraes Sarmento, Pasta Encontro Nacional de Dirigentes de Museus I e II. Rio de Janeiro: Unirio, 1975.

RÚSSIO, Waldisa. [Programação do Curso de Museologia Popular ministrado na Babia]. Arquivo do Instituto de Estudos Brasileiros da Universidade de São Paulo, Fundo Waldisa Rússio, Caixa 097, Documento 30.0106. São Paulo: IEB, 1984 b. 
SUPERINTENDÊNCIA DE MUSEUS DE MINAS GERAIS. [Correspondência]. Arquivo do Instituto de Estudos Brasileiros da Universidade de São Paulo, Fundo Waldisa Rússio, Caixa 081, Documento 18.0028. São Paulo: IEB, 1985.

LIVROS, ARTIGOS E TESES

ARANTES, Antonio Augusto (org.). Produzindo o passado: estratégias de conservação do patrimônio cultural. São Paulo: Brasiliense, 1984.

ARAUJO, Marcelo Mattos. Waldisa Rússio Camargo Guarnieri: agente da utopia. In: BRUNO, Maria Cristina Oliveira (org.). Waldisa Rússio Camargo Guarnieri: textos e contextos de uma trajetória profissional. São Paulo: Pinacoteca do Estado, 2010. v. 2, p. 103-141.

BOURDIEU, Pierre. Os usos sociais da ciência: por uma sociologia clínica do campo científico. São Paulo: Unesp, 2003.

BRASIL. Lei $\mathrm{n}^{\circ}$ 7.287, de 18 de dezembro de 1984. Dispõe sobre a Regulamentação da Profissão de Museólogo. Diário Oficial da União, Brasília, DF, p. 19033, 19 dez. 1984.

BRASIL. [Constituição (1988)]. Constituição da República Federativa do Brasil de 1988. Diário Oficial da União, Brasília, DF, 5 out. 1988. Disponível em: <https://bit.ly/3oDIIt7>. Acesso em: 10 jan. 2020.

BRASIL. Ministério da Cultura. Política Nacional de Museus: relatório de gestão 2003-2004. Brasília, DF: Ministério da Cultura, 2005.

BRASIL. Lei $\mathrm{n}^{\circ}$ 11.904, de 14 de janeiro de 2009. Institui o Estatuto de Museus e dá outras providências. Diário Oficial da União, Brasília, DF, p. 1, 15 jan. 2009.

BRUNO, Maria Cristina Oliveira (org.). O Icom/Brasil e o pensamento museológico brasileiro: documentos selecionados. São Paulo: Pinacoteca do Estado, 2010a. 2 v.

BRUNO, Maria Cristina Oliveira (org.). Waldisa Rússio Camargo Guarnieri: textos e contextos de uma trajetória profissional. São Paulo: Pinacoteca do Estado, 2010b. v. 1.

BRUNO, Maria Cristina Oliveira (org.). Waldisa Rússio Camargo Guarnieri: textos e contextos de uma trajetória profissional. São Paulo: Pinacoteca do Estado, 2010c. v. 2.

CAMPOS, Yussef Daibert Salomão de. A dimensão política do patrimônio cultural na Constituinte de 1987-1988. 2015. 242 f. Tese (Doutorado em História) - Universidade Federal de Juiz de Fora, Juiz de Fora, 2015. 
CARVALHO, Luciana Menezes de. Do museu à museologia: constituição e consolidação de uma disciplina. 2017. 215 p. Tese (Doutorado em Museologia e Patrimônio) - Universidade Federal do Estado do Rio de Janeiro, Museu de Astronomia e Ciências Afins, Rio de Janeiro, 2017.

CHAGAS, Mario de Souza. Há uma gota de sangue em cada museu: a ótica museológica de Mário de Andrade. Chapecó: Argos, 2006.

COELHO, Priscilla Arigoni. Metáforas em rede no processo de institucionalização: um estudo sobre memória e discurso da Museologia no Brasil (1932 a 1985). 2015. 261 p. Tese (Doutorado em Memória Social) - Universidade Federal do Estado do Rio de Janeiro, Rio de Janeiro, 2015.

COUTINHO, Maria Inês Lopes. Waldisa, o curso de Museologia e o Alunado. In: BRUNO, Maria Cristina Oliveira (org.). Waldisa Rússio Camargo Guarnieri: textos e contextos de uma trajetória profissional. São Paulo: Pinacoteca do Estado, 2010. v. 2, p. 9-46.

DUARTE CÂNDIDO, Manuelina Maria. Ondas do pensamento museológico brasileiro. Cadernos de Sociomuseologia. Lisboa: ULHT, n. 20, 2003.

GOUVEIA, Inês. Waldisa Rússio e a política no campo museológico. 2018. 375 p. Tese (Doutorado em Museologia e Patrimônio) - Universidade Federal do Estado do Rio de Janeiro, Museu de Astronomia e Ciências Afins, Rio de Janeiro, 2018.

INSTITUTO JOAQUIM NABUCO DE PESQUISAS SOCIAIS. Subsídios para a implantação de uma política museológica brasileira. Recife: Instituto Joaquim Nabuco, 1976.

JULIÃO, Letícia. Apontamentos sobre a história do museu. In: CADERNO de diretrizes museológicas. Belo Horizonte: Secretaria de Estado da Cultura, 2001. p. 17-30.

MAGALHÃES, Aline Montenegro. Culto da saudade na Casa do Brasil: Gustavo Barroso e o Museu Histórico Nacional. Fortaleza: Museu do Ceará, 2006. (Coleção Outras Histórias, 49).

MORO, Fernanda de Camargo e Almeida; NOVAES, Lourdes M. Martins do Rego. Introdução ao ensino dirigido de museologia. Rio de Janeiro: Amicom, 1977.

MORO, Fernanda de Camargo e Almeida; NOVAES, Lourdes M. Martins do Rego. Icom e Brasil: um diálogo: lembranças (1946-1993). In: BRUNO, Maria Cristina Oliveira (org.). O Icom/Brasil e o pensamento museológico brasileiro: documentos selecionados. São Paulo: Pinacoteca do Estado, 2010. v. 1, p. 31-81.

RODRIGUES, Marly. Imagens do passado: a instituição do patrimônio em São Paulo: 19691987. São Paulo: Imprensa Oficial do Estado, 2000.

RÚSSIO, Waldisa. Waldisa Rússio. MuWoP: Museological Working Papers, Stockholm, n. 2, p. 56-57, 1981. 
RÚSSIO, Waldisa. Texto III - Waldisa Rússio. In: ARANTES, Antonio Augusto (org.). Produzindo o passado: estratégias de conservação do patrimônio cultural. São Paulo: Brasiliense, 1984c. p. 59-78.

RÚSSIO, Waldisa. A difusão do patrimônio: novas experiências em museus, programas educativos e promoção cultural. In: BRUNO, Maria Cristina Oliveira (org.). Waldisa Rússio Camargo Guarnieri: textos e contextos de uma trajetória profissional. São Paulo: Pinacoteca do Estado, 2010a. v. 1, p. 164-175.

RÚSSIO, Waldisa. Alguns aspectos do patrimônio cultural: o patrimônio industrial. In: BRUNO, Maria Cristina Oliveira (org.). Waldisa Rússio Camargo Guarnieri: textos e contextos de uma trajetória profissional. São Paulo: Pinacoteca do Estado, 2010b. v. 1, p. 147-159.

RÚSSIO, Waldisa. Museu: uma organização em face das expectativas do mundo atual. In: BRUNO, Maria Cristina Oliveira (org.). Waldisa Rússio Camargo Guarnieri: textos e contextos de uma trajetória profissional. São Paulo: Pinacoteca do Estado, 2010c. v. 1, p. 45-56.

RÚSSIO, Waldisa. Sistema da museologia. In: BRUNO, Maria Cristina Oliveira (org.). Waldisa Rússio Camargo Guarnieri: textos e contextos de uma trajetória profissional. São Paulo: Pinacoteca do Estado, 2010d. v. 1, p. 127-136.

SÁ, Ivan Coelho de. Institucionalização das práticas museológicas: oitenta anos do Curso de Museus. In: MAGALHÃES, Aline Montenegro; BEZERRA, Rafael Zamorano. 90 anos do Museu Histórico Nacional em debate (1922-2012). Rio de Janeiro: MHN, 2014. p. 223-243.

SANTOS, Maria Célia Teixeira Moura. Entrevista ao prof. Mário de Souza Chagas. Cadernos de Sociomuseologia, Lisboa, n. 18, p. 7-34, 2002.

SOARES, Bruno Brulon; CARVALHO, Luciana Menezes de; CRUZ, Henrique de Vasconcelos. O nascimento da Museologia: confluências e tendências do campo museológico no Brasil. In: MAGAlHÃES, Aline Montenegro; BEZERRA, Rafael Zamorano (orgs.). Anais do Museu Histórico Nacional: 90 anos do Museu Histórico Nacional em debate (1922-2012). Rio de Janeiro: Museu Histórico Nacional, 2014. p. 244-262.

Artigo apresentado em: 2/4/2020. Aprovado em 2/9/2020. (cc) BY

All the contents of this journal, except where otherwise noted, is licensed under a Creative Commons Attribution Licens 